\title{
AS CONTRIBUIÇÕES DA ACP AO SABER PSICOPEDAGÓGICO
}

\author{
LAS CONTRIBUCIONES A SABER ACP PSICOPEDAGÓGICO
}

ACP'S CONTRIBUTIONS TO PSYCHOPEDAGOGICAL KNOWLEDGE

\author{
Benjamim da Silva AMORIM ${ }^{1}$
}

RESUMO: O presente trabalho pretende verificar como a Abordagem Centrada na Pessoa poderá contribuir com a Psicopedagogia. A Psicopedagogia é uma área científica recente e ainda busca uma teoria para fundamentar sua prática. Desenvolvida a partir de diversas outras áreas do conhecimento, tem sua base principal na Pedagogia e na Psicologia, e como objetivos compreender a construção do conhecimento com todos os fatores que a influenciam, facilitando o aprendizado e identificando o que impede o sujeito de aprender. Porém, este é um conceito novo e só através do estudo da história da Psicopedagogia pode-se entender como ocorreu à evolução desta área. Com a mudança de paradigma, a Abordagem Centrada na Pessoa (ACP), corrente de pensamento psicológico criada por Carl Rogers traz outra forma de se compreender a aprendizagem que passou a envolver significância e experiência, e entendimento de que o sujeito aprendente possui todas as potencialidades para aprender e é por meio de uma comunicação empática que o psicopedagogo age como um facilitador para $o$ aprendizado e a mudança do aluno. Conclui-se que a prática psicopedagógica aplicada com base na teoria da Abordagem Centrada na Pessoa pode melhorar os resultados das intervenções nos processos de dificuldade de aprendizagem.

PALAVRAS-CHAVE: Psicopedagogia. Abordagem Centrada na Pessoa. Aprendizagem significativa.

RESUMEN: El objetivo de este trabajo es verificar cómo el Enfoque Centrado en la Persona puede contribuir a la Psicopedagogía. La Psicopedagogía es un nuevo campo científico y aún busca una teoría para apoyar su práctica. Desarrollado a partir de muchas otras áreas del conocimiento, tiene su base principal en Pedagogía y Psicología, y lo más objetiva para entender la construcción del conocimiento con todos los factores que influyen en ella, lo que facilita el aprendizaje y la identificación de lo que impide que el objeto de aprender. Pero este es un nuevo concepto y sólo mediante el estudio de la historia de la Psicopedagía se puede entender como fue la evolución de esta área. Con el cambio de paradigma, el Enfoque Centrado en la Persona (ACP), la escuela de pensamiento psicológico creado por Carl Rogers trae otra manera de entender el aprendizaje que tiene que implicar importancia y la experiencia y la comprensión del alumno sujeto tiene todo el potencial y de aprender es a través de una comunicación empática que el psicopedagogo actúa como un facilitador para el aprendizaje y el cambio de los estudiantes. Se concluye que la práctica psicopedagógica aplican en función de la teoría del Enfoque Centrado persona puede mejorar los resultados de las intervenciones en la dificultad de los procesos de aprendizaje.

${ }^{1}$ Doutorando em Psicologia da Educação pela Universidade de Lisboa Portugal. Graduado em Psicologia pela Universidade FUMEC, Brasil. Pós-graduado em Psicoterapia Humanista - Abordagem Centrada na Pessoa - pela Universidade FUMEC, Brasil. Especialista em Psicopedagogia Clínica e Institucional pela ESAB, Brasil. Doutorando em Psicologia da Educação pela Universidade de Lisboa Portugal. 
PALABRAS CLAVE: Psicopedagogía. Enfoque Centrado en la Persona. aprendizaje significativo.

ABSTRACT: This paper aims to verify how the Person Centered Approach can contribute to the Educational Psychology, seeking to know the history of Psychology in Brazil and its assumptions. The Educational Psychology is a new scientific field and still seeks a theory to support their practice. Developed from many other areas of knowledge, has its main base in Pedagogy and Psychology, and as objective to understand the construction of knowledge with all the factors that influence it, facilitating learning and identifying what prevents the subject to learn. But this is a new concept and only by studying the history of Psychology can be understood as was the evolution of this area. With the paradigm shift, the Person Centered Approach (PCA), psychological school of thought created by Carl Rogers brings another way to understand the learning that has to involve significance and experience and understanding of the subject learner has all the potential and to learn is through an empathic communication that the educational psychologist acts as a facilitator for learning and change student. It is concluded that the psychopedagogical practice applied based on the theory of the Person Centered Approach can improve the results of interventions in the difficulty of learning processes.

KEYWORDS: Educational Psychology. Person Centered Approach. Meaningful learning.

\section{Introdução}

A Psicopedagogia é uma área científica recente e ainda busca uma teoria para fundamentar sua prática. É um conhecimento multidisciplinar, contudo, sua base principal é a Pedagogia e a Psicologia. A Psicopedagogia objetiva compreender a construção do conhecimento com todos os fatores que a influenciam, facilitando o aprendizado e identificando o que impede o sujeito de aprender. Porém, este é um conceito novo e só através do estudo da história da Psicopedagogia pode-se entender como ocorreu à evolução desta área. Abordagem Centrada na Pessoa (ACP), corrente de pensamento psicológico criada por Carl Rogers traz outra forma de se compreender a aprendizagem. Percebemos que o sujeito aprendente possui todas as potencialidades para aprender e é por meio de uma comunicação empática que o psicopedagogo age como um facilitador para o aprendizado e a mudança do aluno.

Para articular o fenômeno em questão, nos apropriamos dos conhecimentos da Abordagem Centrada na Pessoa, com o objetivo de sugerir ações escolares de atividades psicopedagógicas de apoio aos alunos com dificuldades de aprendizagens e colaborar 
com as autoridades escolares sobre esta temática sob a perspectiva da Psicologia Humanista.

\section{Pressupostos da Psicopedagogia}

A Psicopedagogia surge inicialmente com o objetivo de resolver o fracasso escolar e de atenuar as dificuldades de aprendizagem. (SILVA, 2010). Com sua evolução, o objeto de estudo da Psicopedagogia se modificou, passando a ter uma abordagem mais ampla, procurando entender todo o processo de aprendizagem, como ocorre como prevenir ou tratar as dificuldades de aprendizagem (BOSSA, 2002 apud ALVES e BOSSA, 2006).

A Psicopedagogia tem seu início entre as décadas de 20 e 40, como Psicopedagogia Clínica instituída nos primeiros centros de Psicopedagogia de Paris, fundados por JulietteFavez-Boutonier e George Mauco (RAMOS, 2007). De acordo com Mauco, o termo psicopedagógico substituiu o "médico-pedagógico", para facilitar o atendimento (MASINI, 2006). Neste período, o foco da Psicopedagogia estava na criança com dificuldades de aprendizagem. A proposta era adaptar a criança à sociedade. Estes centros tinham equipes com profissionais de diferentes áreas (MASINI, 2006). A intervenção era com base em uma “[...] investigação da vida familiar, das relações conjugais, das condições de vida, dos métodos educativos, dos resultados dos testes de QI da pessoa" (RAMOS, 2007, p. 10).

A partir da década de 60, na França, a metodologia aplicada nos centros passa a ser discutida. Para Vasques e Oury, o diagnóstico da criança feito de forma descontextualizada poderia comparar a criança a padrões abstratos (MASINI, 2006). A adaptação da criança à escola e à sociedade era questionada (MASINI, 2006). Bloch Laine, questionava a ênfase apenas em problemas físicos ou psíquicos da criança, devido ao expressivo número de crianças com fracasso escolar, o que colocava em dúvida este sistema de diagnóstico (MASINI, 2006). Apesar das críticas, este modelo foi importado para a América do Sul (RAMOS, 2007).

No Brasil a Psicopedagogia seguiu as abordagens aplicadas na Europa (MASINI, 2006). A Psicopedagogia chega ao Brasil durante a década de 60 de forma secreta (ANDRADE, 2004 apud RAMOS, 2007), devido ao governo ditatorial vigente na 
época. Com características similares a Psicopedagogia aplicada na Europa, a Psicopedagogia brasileira se desenvolveu a partir de uma visão médico-pedagógico (RAMOS, 2007), em que o problema estava todo centrado no aluno. Tais metodologias enfatizavam mais a prática do que qualquer base teórica, esses primeiros profissionais eram educadores e "[...] na própria prática eram encontradas as técnicas que melhor atendessem à necessidade do aprendiz para reeducá-lo de forma mais eficaz e específica" (MASINI, 2006, p. 251). De acordo com Ramos (2007), no Brasil a Psicopedagogia se desenvolveu com base em uma visão orgânica e patológica das dificuldades de aprendizagem, no qual se buscava diagnosticar as disfunções neurológicas, denominadas "Disfunção Cerebral Mínima", que pudessem levar a alterações de comportamento. Essa forma de se fazer psicopedagogia chegou às escolas e consequentemente levou as crianças com algum tipo de dificuldade a serem rotuladas (SCOZ, 1994 apud RAMOS, 2007) e tratadas com preconceito. Essa Psicopedagogia baseada no diagnóstico de problemas patológicos ocultou as outras causas de um problema mais profundo e complexo que é o fracasso escolar, colocando toda a culpa do fracasso no próprio aluno que apresentava a dificuldade de aprendizagem (RAMOS, 2007).

A partir da década de 70, a necessidade de pesquisas sobre a aprendizagem e a dificuldade de aprendizagem, fez surgir os cursos de capacitação de profissionais na área, que visavam uma formação complementar a psicólogos e pedagogos (RAMOS, 2007). Eram cursos de curta duração, contudo, a partir de 2000 se expandiu essa formação em Psicopedagogia para outros cursos, como graduação, mestrado e doutorado (RAMOS, 2007). A partir da década de 80, no Brasil também começou a questionar este sistema-diagnóstico que não explicava o fracasso escolar e passando a enfatizar o aspecto social da aprendizagem. Com este novo enfoque, os problemas de aprendizagem e o fracasso escolar, que antes eram exclusivos do aluno, passaram a incluir questões relacionadas à escola, como sua estrutura e métodos pedagógicos, e aos educadores e sua formação profissional (MASINI, 2006).

\section{Psicopedagogia como teoria}

A Psicopedagogia é uma área multi e interdisciplinar que resulta da integração da Psicologia com a Pedagogia, porém, caracteriza-se por um saber independente que possui seus próprios instrumentos (SILVA, 2010) e seu próprio objeto de estudo 
(ALVES e BOSSA, 2006). Apesar da evolução, a Psicopedagogia ainda não conseguiu se firmar como uma ciência, estando numa fase de pré-saber (SILVA, 2010): “A falta de nitidez conceitual, a indefinição do corpus teórico psicopedagógico convive no Brasil com uma prática psicopedagógica com resultados bastante eficazes (SILVA, 2010, p. 18-19). A falta de uma teoria se deve pela grande influência de diversas áreas que são bases para a prática psicopedagógica (RAMOS, 2007; BOSSA, 2008). Para Bossa (2008), isto dificulta a articulação entre esses diversos conhecimentos, fazendo com que a Psicopedagogia perca seu foco. Outra questão que também impede que a Psicopedagogia se estabeleça como um saber consolidado é o fato de ainda basear-se no empirismo (RAMOS, 2007).

A Psicopedagogia atua nas dificuldades de aprendizagem procurando entender o fracasso escolar e no processo de aprendizagem como um todo, analisando todos os fatores que o influenciam (RAMOS, 2007). De acordo com Silva (2010) a Psicopedagogia é um campo do conhecimento que tem por objeto o ser cognoscente e por objetivo fundamental facilitar a construção da individuação e da autonomia do eu cognoscente identificando e clarificando os obstáculos que impedem que esta construção se faça. Como ser cognoscente entende-se o sujeito em que se dá o processo de aprendizagem, o ser no qual ocorre o processo de conhecimento (SILVA, 2010), ou seja, o sujeito autor, aquele que constrói seu pensamento, que vive e está inserido em um contexto (BOSSA; ALVES, 2006).

Segundo Bossa (2008) a Psicopedagogia caracteriza-se por um raciocínio diagnóstico e uma metodologia de intervenção que busca olhar o sujeito na relação com o objeto de conhecimento em situação de aprendizagem; busca considerar sujeito e objeto como entidades indissociáveis; conceber o sujeito em seu contexto sociohistórico; admitir a possibilidade de um conhecimento transdisciplinar, embora ele se tenha construído na perspectiva interdisciplinar; e ter a clínica das dificuldades de aprendizagem como espaço privilegiado para o desenvolvimento da teoria psicopedagógica. Tendo como referência estes novos conceitos podemos compreender a necessidade de se olhar o sujeito aprendente de forma particularizada, pois o processo de aprendizagem ocorre de forma individual, com caráter subjetivo. E é neste sentido que a Abordagem Centrada na Pessoa se insere na Psicopedagogia auxiliando a construção do conhecimento e facilitando o aprendizado. 


\section{O Processo de Aprendizagem}

A aprendizagem deve ser entendida como um processo, que se inicia com o nascimento e acompanha o sujeito até a sua morte (MASINI, 2006). Para Campos (1994) a aprendizagem está relacionada à apropriação e domínio do objeto de conhecimento. Conduz o ser humano a transformações a partir "[...] das inter-relações sociais e interações ambientais no contexto de vida do indivíduo e são constituídas pelas aquisições de habilidades, raciocínios, atitudes, valores, vontades, interesses, aspirações, integração, participação e realização.” (MASINI, 2006, p. 255). Portanto, o processo de aprendizagem se relaciona com a transmissão da cultura através das gerações, o que é uma definição mais ampla da palavra educação (PAIN, 1992).

De acordo com Pain (1992) podemos atribuir à educação quatro funções interdependentes: (1) função mantenedora: pela aprendizagem se transmite a cultura de uma civilização, o que permite a continuidade da espécie humana; (2) função socializadora: as normas de uma sociedade são transmitidas através da aprendizagem; (3) função repressora: garante a reprodução da sociedade, conservando e reproduzindo os grupos sociais e (4) função transformadora: que possui um caráter libertador, isto é, a educação permite que o indivíduo modifique a sociedade. Para Pain (1992) o processo de aprendizagem tem como estrutura três diferentes dimensões, biológica, cognitiva e social, ou seja, “[...] nesse lugar do processo de aprendizagem coincidem um momento histórico, um organismo, uma etapa genética da inteligência e um sujeito associado a outras tantas estruturas teóricas [...]" (PAIN, 1992, p. 15).

Confirmando esta visão, Rogers (1985) traz alguns conceitos importantes sobre ensinar e aprender: (1) para que o ocorra aprendizagem é preciso que se deixe o aluno aprender; (2) a figura daquele que ensina não deve ser a de uma pessoa autoritária; (3) a aprendizagem deve ter algum sentido, ser significante e cheia de sentimentos, e não apenas envolver a mente; (4) a aprendizagem progride de forma acelerada quando possui um significado prático para o que aprende e não para aquele que ensina; (5) a aprendizagem envolve a experiência e (6) a aprendizagem é auto-iniciada, difusa e avaliada pelo aprendente, isto é, parte do interior do aluno a apreensão e a compreensão, o que se aprende altera seu comportamento e é aquele que aprende que decide se a aprendizagem está de acordo com suas necessidades. Portanto, o principal da aprendizagem é o seu significado: “a aprendizagem significante combina o lógico e o 
intuitivo, o intelecto e os sentimentos, o conceito e a experiência, a ideia e o significado. Quando aprendemos dessa maneira, somos integrais, [...]” (ROGERS, 1985, p. 30).

\section{A Psicopedagogia e a Abordagem Centrada na Pessoa}

Carl Rogers foi um psicólogo e professor norte-americano, que fundou a Terapia Centrada no Cliente e desenvolveu o pensamento psicológico sobre a Abordagem Centrada na Pessoa. Suas ideias foram inicialmente sugeridas para a psicoterapia, porém, se difundiram para diversas áreas, como as Organizações, a Educação e as escolas (GOBBI et al., 2005. Rogers encontra em diferentes profissionais a mesma linha de pensamentos que a sua. Na educação isto aconteceu com maior profundidade, como por exemplo, com Paulo Freire em sua obra A Pedagogia do Oprimido, Rogers identifica vários princípios semelhantes aos seus, como: valorização das atitudes facilitadoras, os sentimentos expressos por cada componente do grupo, as experiências, entre outros (ROGERS, 1989).

\section{A Psicologia Humanista}

A Psicologia Humanista foi inserida nos Estados Unidos por Abraham Maslow e Carl Rogers, nas décadas de 50 e 60, como oposição à Psicanálise e ao Behaviorismo, e com um sentido amplo de revalorização do ser humano, podendo-se assim englobar também a Psicologia Existencial (GOBBI et al., 2005). Este movimento caracteriza-se por (JUSTO, 1987 apud GOBBI et al., 2005):

- Visão total do ser humano;

- Visualizar o homem de forma otimista e positiva, com potencialidades;

- O homem ser intencional, ele procura, a um tempo, conservação e desequilíbrio;

- Enfatizar a subjetividade do ser humano;

- O homem ser consciente, e como tal tem capacidade de escolha;

- O homem um ser social, que expressa sua natureza na relação com o outro;

- Enfatizar as características mais elevadas do ser humano, tais como, criatividade, afeto, autonomia etc.;

- Apresentar o conceito de Self. 
A Psicologia Humanista tem como base assuntos como liberdade, responsabilidade e interação, "a Psicologia Humanista se fundamenta basicamente numa preocupação com o homem, no sentido de valorizar sua existência e buscar a sua essência naquilo que ele possui de mais íntimo e particular: sua experiência, sua vivência." (GOBBI et al., 2005, p. 125).

\section{A Abordagem Centrada na Pessoa}

A Abordagem Centrada na Pessoa (ACP) representa uma evolução das ideias e pensamentos de Rogers. A obra de referência é Personal Power (GOBBI et al., 2005). De acordo com Hart e Tomlison (1970) e Wood (1983), citados por Gobbi (2005) podese dividir a evolução de seus pensamentos em três fases: 1) Psicoterapia Não-Diretiva (1940-1950): destaca-se a não-diretividade e o insigth do cliente. A obra de referência é o livro "Psicoterapia e Consulta Psicológica" de 1942; 2) Terapia Centrada no Cliente (1950/1957) nesta fase Rogers passa a ter o cliente como o foco e, o terapeuta possui um desempenho mais ativo. A principal obra deste período foi "Psicoterapia Centrada no Cliente" de 1951. É nesta fase que surgem as condições básicas de um ambiente favorável ao crescimento e à mudança: a empatia, a autenticidade e a aceitação positiva incondicional. É também neste período que Rogers configura o conceito de Tendência à Atualização, que é depois mostrada como parte de um conceito mais amplo, a Tendência Formativa (BARRETO, 2005). E (3) Psicoterapia Experiencial (1957-1970): em que o cliente com a ajuda do terapeuta deve buscar uma maior congruência do self e do desenvolvimento relacional a partir de suas experiências. A obra de referência é o livro "Torna-se Pessoa" de 1961.

Em 1959, Rogers organizou a "Teoria da Personalidade", a partir de teorias como a fenomenologia e a teoria organísmica da personalidade (BARRETO, 2005). Após 1970, Rogers publica diversos livros, se dedica as atividades de grupo e caminha a uma terapia fenomenológica, esta fase de acordo com Moreira (1990 apud GOBBI et al., 2005) pode-se definir com uma "Fase Coletiva" que vai de 1970 a 1985, neste período ele se preocupa com questões sobre o futuro do homem e do mundo. Neste período, entre as décadas de 70 e 80 , Rogers, concebe seus pensamentos a partir dos movimentos de grupos e encontros de comunidade (CURY, 1987 apud GOBBI et al., 2005). Como suas ideias evoluíram, a nomenclatura utilizada também, assim, o termo cliente deixou de ser usado em detrimento do termo pessoa, que possui um sentido mais 
amplo. Desta forma, Rogers elaborou a Abordagem Centrada na Pessoa, definida como "[...] denominação mais ampla de uma perspectiva de homem e das relações humanas, é uma atitude, é uma maneira de abordar os problemas humanos, [...]” (BARRETO, 2005, p. 168).

Os princípios da ACP são utilizados na área de educação e no trabalho com grupos. Em 1969 com a publicação do livro "Liberdade para Aprender”, Rogers traz sua visão sobre as teorias humanistas aplicadas à educação. A partir destas experiências, Rogers definiu as condições para crescimento, condições estas, que devem estar presentes na psicoterapia e com as quais vários estudiosos da psicologia moderna concordam. Desta forma, para se ter um ambiente que possibilite que o outro cresça, ou seja, com um clima facilitador de crescimento, três condições devem estar presentes: aceitação incondicional, congruência e compreensão empática (ROGERS, 1983), fatores também indispensáveis para um bom aprendizado na ótica da Aprendizagem Centrada no Aluno (ROGERS, 1985).

\section{Fundamentos da Abordagem Centrada na Pessoa e a Psicopedagogia}

A Abordagem Centrada na Pessoa não pretende ser de acordo com Rogers uma filosofia nem uma teoria, mas uma forma específica de entrar em relação com outro, com base "numa crença na potencialidade interna dos organismos [...] e num respeito pela individualidade e singularidade humanas" (GOBBI et al., 2005, p. 16). Desta forma, são três os pressupostos básicos da ACP: (1) uma concepção do homem alicerçada nos princípios da corrente humanista da Psicologia, com "uma visão do homem como sendo, em essência, um organismo digno de confiança" (ROGERS, 1989, p.16); (2) uma abordagem fenomenológica que privilegia a experiência subjetiva da pessoa, entendendo que o conhecimento que se tem do outro acontece a partir da compreensão do seu quadro de referências; e (3) uma forma de entrar em relação que só pode acontecer a partir de um encontro entre pessoas. Além disto, é fundamental para a compreensão de sua teoria os conceitos de: Tendência Atualizante e a Não-Diretividade.

- Tendência Atualizante: Este é o eixo central da ACP, já que é ela que conduz não só à satisfação das necessidades básicas do organismo, como também às mais complexas (ROGERS, 1975). Para Rogers (1977) todo o organismo é movido por uma tendência favorável à sua conservação e enriquecimento. A tendência atualizante não visa somente a manutenção das condições elementares de subsistência como as 
necessidades de ar, alimentação, etc. Ela preside, igualmente, atividades mais complexas e mais evoluídas tais como a diferenciação crescente dos órgãos e funções; a revalorização do ser por meio de aprendizagens de ordem intelectual, social, prática (ROGERS; KINGET, 1977 apud GOBBI et al., 2005, p. 145). Para Rogers, "quer o estímulo provenha de dentro ou de fora, quer o ambiente seja favorável ou desfavorável, os comportamentos de um organismo serão dirigidos no sentido dele manter-se, crescer ou reproduzir-se.” (ROGERS, 1989, p. 226). Para Rogers (1983), portanto, apenas destruindo o organismo é que se consegue acabar com esta tendência. Segundo o mesmo autor, sempre que esta consonância não acontece, a pessoa entra em estado de incongruência, ou seja, gera um desequilíbrio entre a experiência real e a simbólica gerando um comportamento desajustado. O psicopedagogo pode criar um ambiente para que essa tendência se realize, como uma tendência direcional positiva que conduza ao crescimento.

- Não-Diretividade: este modelo posteriormente denominado Terapia Centrada no Cliente e apenas mais tarde como Abordagem Centrada na Pessoa. A definição de não-diretividade, segundo Rogers passa pelo acreditar que "[...] o indivíduo tem dentro de si amplos recursos para auto compreensão, para alterar seu autoconceito, suas atitudes e seu comportamento autodirigido [...]" (ROGERS, 1989, p.16). A proposta de não-direção de Rogers não se baseava em ausência de diretivas, mas numa mudança saindo do poder do terapeuta e caminhando em direção a responsabilidade do cliente (GOBBI et al., 2005). Os conceitos de não-direção e auto direção são mais fáceis de entender quando conceituamos liberdade de acordo com Rogers, uma liberdade de aprender, interna, em que tudo de um ambiente pode ser retirado do indivíduo, exceto suas liberdades humanas, que são suas escolhas, a determinação de um caminho a seguir (ROGERS, 1985).

O psicopedagogo, um facilitador da aprendizagem, não se encontra no processo de atendimento de alunos com dificuldades de aprendizagem apenas para realizar um diagnóstico e determinar a dificuldade do estudante e o que deve aprender, suas atitudes devem ir além da aplicação de técnicas e métodos. O último pressuposto da $\mathrm{ACP}$, uma forma de entrar em relação que só pode acontecer a partir de um encontro entre pessoas, traz uma ideia que Rogers (1982) deu um relevo particular. Assim, enumerou e definiu um conjunto de atitudes que considerou facilitadoras do processo de comunicação interhumana. No caso específico da temática em referência, a qualidade de relação que se estabelece no contexto pedagógico, nomeadamente as atitudes do 
professor/psicopedagogo para com o aluno, determinam não só o nível de qualidade da aprendizagem, como também o próprio desenvolvimento pessoal do aluno.

Consideração Positiva Incondicional: Esta se traduz pela aceitação incondicional da pessoa por parte da outra, tal como ela é sem juízos de valor ou críticas a priori (ROGERS, 1985). Para Rogers (1983) com esta atitude o terapeuta cria um ambiente de segurança e liberdade para que o outro expresse seus sentimentos e uma crença nas potencialidades daquele indivíduo (GOBBI et al., 2005). Desta forma, aquele aluno que se vê apenas de forma negativa e possui uma dificuldade em se aceitar e de ser o que é, pode passar por uma mudança, de autoaceitação e consideração positiva de si (GOBBI et al., 2002).

Compreensão empática: A compreensão empática foi um termo utilizado por Rogers em vez de apenas empatia devido a seu significado mais amplo (GOBBI et al., 2005). Rogers (1977) definiu compreensão empática como: Capacidade de se imergir no mundo subjetivo do outro e de participar na sua experiência, na extensão em que a comunicação verbal ou não verbal o permite. É a capacidade de se colocar verdadeiramente no lugar do outro, de ver o mundo como ele o vê (ROGERS e KINGET, 1977 apud GOBBI et al., 2005, p. 47.

Congruência: $O$ termo congruência pretende indicar o estado em que o terapeuta deve se encontrar de coerência, integral e congruente, a qual se traduz na sua capacidade de aceitar os sentimentos, as atitudes, as experiências, de se ser genuíno e integrado na relação com o outro (ROGERS, 1985). "Quanto mais o terapeuta for ele mesmo na relação com o outro, quanto mais puder remover as barreiras profissionais ou pessoais, maior a probabilidade de que o cliente mude e cresça de um modo construtivo.” (ROGERS, 1983, p. 38). A autenticidade do terapeuta faz com que o cliente também se torne mais autêntico. Porém, quando o indivíduo sente alguma ameaça ou um clima ameaçador, ou seja, sente um medo da desaprovação e tenta manter um comportamento apenas para agradar aos outros, a autenticidade do aluno fica em segundo plano, este passa a demonstrar uma baixa autoestima. Entretanto, é o próprio aluno com o auxílio do facilitador ou psicodagogo que deve buscar e descobrir o que o impede de aprender e o leva a angústia ou ameaça e a partir deste ponto modificar seu comportamento. O psicopedagogo somente indicará ao aluno o caminho a seguir para que ele próprio descubra como aprender, pois, somente a pessoa é capaz de ter conhecimento sobre si. Rogers (1985) defende que, se estas atitudes ou condições facilitadoras, estiverem presentes na relação terapeuta-paciente ou psicopedagogo- 
aluno, a pessoa entra num processo de aceitação de si própria e dos seus sentimentos, tornando-se a pessoa que deseja ser, mais flexível nas suas percepções, adaptando objetivos mais realistas para si própria e, simultaneamente, mais capaz de aceitar os outros

Para Rogers (2001) a capacidade de desenvolvimento faz parte da essência do ser humano. O psicopedagogo que acredita e confia nas potencialidades do outro oferece muitas oportunidades e permite que o estudante faça as suas escolhas e trilhe seu próprio caminho (ROGERS, 1985). Num ambiente favorável que promova o crescimento, o aluno se compromete com o processo de aprender, logo, a aprendizagem se realiza de forma mais profunda, rápida e mais intensa na vida e no comportamento dos alunos, centrando-se a aprendizagem no aluno esta se torna mais vital e criativa (ROGERS, 1983).

Para Rogers (1985) o facilitador precisa aceitar completamente aquele aluno, em todos os seus aspectos, seus sentimentos, tanto aqueles que impedem, quanto àqueles que permitem a aprendizagem, compreender o medo e a dúvida diante de uma situação nova que se apresenta, portanto, o psicopedagogo deve enxergar o aluno como uma pessoa com qualidades e defeitos, com sentimentos e potencialidades. Em seu processo de transformação o aluno integra: [...] neste momento a noção de movimento, de fluxo, de mudança, em todos os aspectos de sua vida psicológica [...] Ele vive no interior de seus sentimentos, conhecendo-os com uma confiança fundamental neles e aceitando-os [...] A comunicação interior dos diferentes aspectos de si mesmo é livre e sem bloqueios. Comunica-se livremente nas relações com os outros, e estas relações não são estereotipadas [...] percebe-se responsável pelos seus problemas. À medida que o psicopedagogo trabalha com o aluno espera-se uma modificação verdadeira, na qual o aluno passa a perceber-se de outra forma, com uma atitude positiva, aberto às novas experiências, realista, na medida em que tem objetivos e ideais acessíveis, passa a se aceitar e também a aceitar mais as outras pessoas (ROGERS, 2001)

A questão mais importante pontuada por Rogers (2001), é que o aluno demonstre interesse por aquilo que possui algum tipo de significado, é uma incumbência do psicopedagogo fazer com que os estudantes demonstrem seus interesses. Quando um aluno com dificuldade passa a ver que pode utilizar a aprendizagem e as experiências do ensino como uma ferramenta na resolução de problemas que o afetam, o aprendizado é crescente (ROGERS, 2001). 
O verdadeiro objetivo de se aprender é tornar o homem instruído e de acordo com Rogers (1985) um ser humano instruído "é aquele que aprendeu como aprender, o que aprendeu a adaptar-se e a mudar, o que se deu conta de que nenhum conhecimento é garantido, mas que apenas o processo de procurar o conhecimento fornece base para a segurança" (ROGERS, 1985, p. 126).

Um dos meios que Rogers faz uso para se alcançar os objetivos de se aprender são os grupos de encontro, que podem ser usados pelo psicopedagogo e os alunos. Os grupos de encontro aplicados segundo a ACP têm como objetivos intensificar o crescimento pessoal, o desenvolvimento e aperfeiçoamento da comunicação e das relações interpessoais, a partir da experienciação (ROGERS, 1979).

Outra forma de se aplicar a ACP é o trabalho com a Ludoterapia que pode ser utilizada com crianças de três até doze anos. Através dos brinquedos e dos jogos, a criança pode expressar seus sentimentos, pensamentos e os problemas que a afligem, utilizando como uma forma de comunicação (GARCIA, 2005). Na ACP a aplicação da Ludoterapia ocorre de forma não-diretiva, a própria criança decide o caminho, nesta abordagem a criança tem responsabilidade e potencial para resolver seus problemas e se modificar (GARCIA, 2005.

\section{Conclusão}

Mais de sete décadas se passaram desde que Rogers publicou suas primeiras ideias, e ainda assim elas parecem nos chocar, pois pouco daquela escola tradicional foi modificada. Quando há uma tentativa de aplicar uma psicologia humanista na escola estas são consideradas experimentais. As dificuldades encontradas por Rogers são ainda as mesmas encontradas por aquele profissional que busca aplicar a Abordagem Centrada na Pessoa dentro de nossas escolas. Ao se trabalhar com alunos com dificuldades de aprendizagem, dar ênfase nos interesses dos alunos, no que representa algo que possui significado e na experiência, conduz-se a uma aprendizagem real, que não será esquecida e que foi realmente compreendida. O mais importante é a construção da relação pessoal entre o psicopedagogo e o aluno, relação que deve ter como base o respeito, a confiança, o apreço, que dependem de certas atitudes expressas pelo psicopedagogo, como a compreensão empática, autenticidade e consideração positiva 
incondicional, e que posteriormente ao longo dos encontros entre eles, o próprio aluno apresentará tais características, culminando com uma modificação de seu comportamento e facilitando o real aprendizado.

\section{REFERÊNCIAS}

ALVES, M. D. F.; BOSSA, N. Psicopedagogia: em busca do sujeito autor. Psicopedagogia on-line: portal da educação e saúde mental. Disponível em: Disponível em: http://www.psicopedagogia.com.br/artigos/. Acesso em: 08 out. 2011.

ANDRADE, M. S. Rumos e diretrizes dos cursos de Psicopedagogia: análise crítica do surgimento da Psicopedagogia na América Latina. Cadernos de Psicopedagogia, v.3, n. 6, p. 70-71, 2004.

AXLINE, V. M. Ludoterapia: a dinâmica do interior da criança. 2 ed. Belo Horizonte: Interlivros, 1984.

BARRETO, C. L. B. T. A evolução da terapia centrada no cliente. In: GOBBI, S. L. et al. Vocabulário e noções básicas da abordagem centrada na pessoa. 2 ed. São Paulo: Vetor, 2005. p. 167-181

BOSSA, N. A. A emergência da Psicopedagogia como ciência. Revista psicopedagia, São Paulo, v. 25, n. 76, 2008 .

BOSSA, N. A. Fracasso Escolar: um olhar psicopedagógico. São Paulo: ARTMED, 2002.

CAMPOS, M. C. M. Psicopedagogo: um generalista-especialista em problemas de aprendizagem. In: Oliveira, Vera B. de; Bossa, Nádia A. (Orgs.) Avaliação psicopedagógica da criança de zero a seis anos. 14 ed. Petrópolis, RJ: Vozes, 1994. p. 208-223.

CURY, V. E. Psicoterapia Centrada na Pessoa: Evolução das Formulações sobre a Relação Terapeuta-Cliente. Dissertação (Mestrado) - Universidade de São Paulo, São Paulo, 1987.

GARCIA, Schirley dos Santos. Diretrizes da Ludoterapia na Abordagem Centrada na Pessoa. In: GOBBI, S. L. e tal.Vocabulário e noções básicas da abordagem centrada na pessoa. 2 ed. São Paulo: Vetor, 2005. p. 183-201

GOBBI, S. L. Carl Rogers: vida e obra. In: GOBBI, S. L. et al.Vocabulário e noções básicas da abordagem centrada na pessoa. 2 ed. São Paulo: Vetor, 2005. p. 261- 271

GOBBI, S. L. et al. Vocabulário e noções básicas da abordagem centrada na pessoa. 2 ed. São Paulo: Vetor, 2005. 277p.

GONÇALVES, L. S. S. Atitudes Empáticas e Aprendizagem - um estudo sobre a relação professor aluno, através do olhar da Abordagem Centrada na Pessoa. 
2008. 242 f. Dissertação (Mestrado). Programa de PósGraduação em Educação, UFRJ Universidade Federal do Rio de Janeiro, Rio de Janeiro, 2008. Disponível em: Acesso em: 25 out. 2011.

JUSTO, H. Cresça e Faça Crescer. Lições de um dos maiores psicólogos: C. Rogers, Canoas: Tipografia e Editora La Salle, 1987.

JUSTO, H. E. “Aprendizagem Centrada no Aluno”. In: GOBBI, S. L. etal.Vocabulário e noções básicas da abordagem centrada na pessoa. 2 ed. São Paulo: Vetor, 2005. p. 203-216

O'HARA M.; AFONSO H. L. FONSECA. Em Busca de Vida: Da Terapia Centrada no Cliente à Abordagem Centrada na Pessoa. São Paulo :Summus, 1983.

MASINI, Elcie F. Salzano. Professional formation in Psychopedagogy: collisions and challenges. Revista Psicopedagia, São Paulo, v. 23, n. 72, 2006 . Disponível em: . Acesso em: 08 out. 2011.

MOREIRA, V. Para Além da Pessoa: uma revisão crítica da psicoterapia de Carl Rogers. Dissertação (Doutorado) - Pontifícia Universidade Católica de São Paulo São Paulo, 1990.

OLIVEIRA, V. B.; Bossa, Nádia A. (Orgs.) Avaliação psicopedagógica da criança de zero a seis anos. 14 ed. Petrópolis, RJ: Vozes, 1994. p. 208-223.

PÀGES, M. Orientação Não-Diretiva em Psicoterapia e em Psicologia Social. Rio de Janeiro: Forense-Universitária/ São Paulo: Editora da Universidade de São Paulo, 1976.

PAIN, S. Diagnóstico e Tratamento dos Problemas de Aprendizagem. Tradução Ana Maria Netto Machado. 4 ed. Porto Alegre: Artes Médicas, 1985. 86 p.

RAMOS, G. P. Psicopedagogia: aparando arestas pela História. VIDYA, Santa Maria, v. 27, n. 1, p. 9-20, jan./jun., 2007.

ROGERS, C. R.; KINGET, G. M. Psicoterapia e Relações Humanas, Belo Horizonte: Interlivros, 1977.

ROGERS, C. R. Grupos de encontro. Tradução Joaquim L. Proença. 3 ed. São Paulo: Martins Fontes, 1979. 165 p.

ROGERS, C. R. Liberdade de aprender em nossa década. Belo Horizonte. Artes Médicas, 1985. 334 p.

ROGERS, C. R. Sobre o Poder Pessoal. Tradução Wilma M. A. Penteado. 3 ed. São Paulo: Martins Fontes, 1989. 273 p.

ROGERS, C. R. Tornar-se Pessoa. Tradução Manuel José do C. Ferreira; AlvamarLamparelli. 5 ed. São Paulo: Martins Fontes, 2001. 489 p.

ROGERS, C. R. Um jeito de ser. Tradução Maria Cristina M. Kupfer, Heloísa Lebrão, Yone S. Patto. 2 reimpressão, São Paulo: Editora Pedagógica e Universitária, 1983. 156 p. 
SCOZ, B. Psicopedagogia e realidade escolar - o problema escolar e de aprendizagem. Petrópolis: Vozes, 1994.

SILVA, M. C. A. Psicopedagogia: a busca de uma fundamentação teórica. 2 ed. São Paulo:

Paz e terra, 2010. 80 p.

TOMLISON, T. M. (Orgs.) New Directions in Cliente-Centered Therapy, Boston: Houghton Mifflin, 1970.

WOOD, J. K. Terapia de Grupo Centrada na Pessoa, in Carl. R. Rogers ; John K. Wood; Maureen M. O'Hara\& Afonso H. L. Fonseca, Em Busca de Vida: Da Terapia Centrada no Cliente à Abordagem Centrada na Pessoa, São Paulo : Summus, 1983

\section{Como referenciar este artigo}

AMORIM, Benjamim da Silva. As contribuições da ACP ao saber psicopedagógico Revista Ibero-Americana de Estudos em Educação, Araraquara/SP, v. 11, n. esp. 3, p.1745-1760, 2016. Disponível em: 〈http://dx.doi.org/10.21723/riaee.v11.n.esp3.9077〉. E-ISSN: 1982-5587.

Submetido em: agosto/2016

Aprovado em: novembro/2016 